\title{
In vivo quantification of removal of asialo-orosomucoid from the circulation in anaesthetized streptozotocin-diabetic rats
}

\author{
M. Appel ${ }^{1}$, P. Potrat ${ }^{1}$, J. Feger ${ }^{1}$, C. Mas-Chamberlin ${ }^{2}$ and G. Durand ${ }^{1}$ \\ 1 Laboratoire de Biochimie, Centre d'Etudes Pharmaceutiques et Biologiques, Université Paris-Sud, and \\ 2 Clinical Research Department, Laboratoire d'Etude et de Recherche Synthalabo, Paris, France
}

\begin{abstract}
Summary. The in vivo kinetic of removal of ${ }^{3} \mathrm{H}$ asialo-orosomucoid from plasma was investigated in control and streptozotocin-diabetic rats after intravenous injection of $1 \mathrm{mg}$ of asialo-orosomucoid/ $100 \mathrm{~g}$ body wt. Michaelis-Menten kinetics of disappearance were observed. In diabetic rats the maximal rate (Vmax) of disappearance of ${ }^{3} \mathrm{H}$ asialo-orosomucoid was decreased by $30 \%$ with no modification of Michaelis constant. Since no accumulation of desialylated orosomucoid in the circulation was observed, the slower rate of removal of ${ }^{3} \mathrm{H}$ asialo-orosomucoid was attributed to a decrease in the num-
\end{abstract}

ber of hepatic asialoglycoprotein receptors which are largely involved in the catabolism of asialoglycoproteins. Our estimate on in vivo maximal rates was 10 - to 20 -fold greater than our previous in vitro estimate of the maximal rate of endocytosis. In contrast, the values of the Michaelis constant obtained in vivo and in vitro were very similar.

Key words: Asialo-orosomucoid, streptozotocin-diabetes, glycoprotein.
A specific receptor which binds and mediates the endocytosis of desialylated glycoproteins is present at the outer surface of hepatocytes $[1,2]$. This receptor-mediated endocytosis is a general phenomenon which concerns all the glycoproteins, provided the sialic acid residues are removed; therefore the galactose residues are at the ultimate position. However, the efficiency of removal from the circulation depends on the structure of the glycan moiety. Asialo-orosomucoid (ASOR), which contains a high percentage of carbohydrates $(40 \%)$, is most rapidly taken up by liver. Furthermore, the asialoglycoproteins receptor expression is affected by the state of an animal and particularly by the growth state of cells [2].

We have recently reported that the binding and uptake of ${ }^{3} \mathrm{H}$ ASOR by hepatocytes from streptozotocindiabetic rats were dramatically altered when compared to their removal by normal rat hepatocytes. This was related to a decrease in the number of cell surface receptors with no modification in the apparent affinity constants [3]. The number of intracellular receptors was also decreased [4]. Since the reported number of cell surface receptors is highly variable, depending on experimental conditions used in regard to liver cell isolation and incubation [5], it seems difficult to predict the in vivo behaviour of injected ${ }^{3} \mathrm{H}$ ASOR from our in vitro results [3]. To this purpose, ${ }^{3} \mathrm{H}$ ASOR was injected intravenously in normal and diabetic rats, and its disappearance from plasma was measured. The presence of partially desialylated orosomucoid in plasma was also investigated.

\section{Materials and methods}

\section{Experimental animals}

Sprague-Dawley rats (male, 51-55 days old) were used for all experiments. Diabetes was induced by a single intravenous injection (dorsal tail vein) of streptozotocin ( $65 \mathrm{mg} / \mathrm{kg}$ body wt.) dissolved immediately before use in $0.2 \mathrm{~mol} / 1$ citrate buffer isotonic, $\mathrm{pH}$ 4.6. Control animals were injected with buffer alone. Fourteen to 20 days after streptozotocin injection, diabetes was determined by a $24 \%$ weight loss, plasmaglucose levels between $5.80 \mathrm{~g} / 1$ to $6.79 \mathrm{~g} / 1$ and glycosuria. No protein and no ketone bodies were detected in urine using albustix (sensitivity $50 \mathrm{mg} / \mathrm{l}$ ) and ketostix (sensitivity $50 \mathrm{mg} / 1$ ) respectively (Ames, Paris, France). Hematocrit was $0.47 \pm 0.03$ and natraemia was $140 \pm$ $2 \mathrm{mmol} / 1$ for control and diabetic rats respectively. Hence the diabetic rats were free of severe acute or chronic complications such as nephropathy and dehydration. The rats had free access to food until the morning of the experiment.

\section{Reagents}

Human orosomucoid was a gift from Dr. Wickerhauser (American Red Cross, NIH, Bethesda, MD, USA). Agarose-immobilized neuraminidase type X.A and streptozotocin were purchased from Sigma 
Chemical Co. (St Louis, MO, USA), tritiated sodium borohydride (specific activity $60 \mathrm{Ci} / \mathrm{mmol}$ ) from Commissariat de l'Energie Atomique (Gif-sur-yvette, France), Dynagel from Comptoir Lyonnais de Verreries Interbio (Lyon, France) and Sephadex G 25 from Pharmacia (Uppsala, Sweden). Sprague-Dawley rats were purchased from Charles River (St Aubin Les Elbeuf, France). All other reagents were laboratory grade and obtained from local sources.

\section{Determination of serum orosomucoid and its desialylation by immunological methods}

Before the injection of ${ }^{3} \mathrm{H}$ ASOR, a blood sample was drawn by the jugular vein and serum orosomucoid was measured by two immunological methods: the radial immunodiffusion method (RID) of Mancini [6] and the electroimmunodiffusion method (EID) of Laurell [7] as described by Biou et al. [8]. The percentage of the underevaluation by electroimmunodiffusion relative to radial immunodiffusion was calculated. Then, using previously established standard curves of the relation between the percentage of desialylation and the percentage of underevaluation, the degree of desialylation of orosomucoid was calculated [8].

\section{Desialylation and radiolabelling of orosomucoid}

Human orosomucoid was desialylated with agarose-immobilized neuraminidase. The reductive methylation of Wilder [9] was used to generate ${ }^{3} \mathrm{H}$ ASOR.

Typically $10 \mathrm{mg}$ of protein in $1 \mathrm{ml}$ of $0.2 \mathrm{~mol} / 1$ sodium borate buffer $\mathrm{pH} 9$ were mixed on ice with $18 \mu \mathrm{l}$ of $3.5 \%$ aqueous formaldehyde and added to a freshly opened ampoule containing $25 \mathrm{mCi}$ of tritiated sodium borohydride. After $30 \mathrm{~min}$, the labelled protein was purified by gel filtration on Sephadex G25, the eluting buffer being $0.005 \mathrm{~mol} / 1 \mathrm{NaHCO} / 0.15 \mathrm{~mol} / 1 \mathrm{NaCl}, \mathrm{pH} 7 .{ }^{3} \mathrm{H}$ ASOR can be stored at $-20^{\circ} \mathrm{C}$ for months with no loss of activity and no degradation. The specific activity was $4 \mathrm{Ci} / \mathrm{mmol}$.

\section{Catheterization and blood sampling}

The animals were anaesthetized with sodium pentobarbital $(50 \mathrm{mg} / \mathrm{kg}$ body wt.). Jugular vein and penial vein were then exposed and cannulated with silastic Dow Corning tubing and PE 50 tubing filled with heparinized saline respectively. A pretest blood sample was taken for the determination of hematocrit and plasma glucose. Doses of $1000 \mu \mathrm{g}$ of ASOR per $100 \mathrm{~g}$ of body weight were injected. At time 0 , the ${ }^{3} \mathrm{H}$ ASOR at a specific radioactivity of $4 \mathrm{Ci} / \mathrm{mmol}$, mixed with unlabelled asialoglycoprotein in a total volume of about $0.5 \mathrm{ml} 0.9 \%$ $\mathrm{NaCl}$, was rapidly injected via the penial catheter. The catheter was flushed through one time with $0.5 \mathrm{ml}$ of saline and heparin to remove any trace of radioactivity. Blood samples $(200 \mu \mathrm{l})$ were taken at sampling times of $1,2,3,4,5,8,10,15,20,30,45$ and $60 \mathrm{~min}$. Blood was aspirated via the jugular catheter first to dispel the heparinized saline and the sample was then drawn into a clean syringe. On the last blood sample, hematocrit was measured. There was no significant haematocrit difference between control and streptozotocin-treated rats, nor between the first and the last samples of the experiment. The amount of radioactivity detected in the urine formed during the experiment represented $1 \mathrm{p} 100$ of the dose injected in control as well as diabetic rats.

\section{Determination of ${ }^{3} \mathrm{H}$ asialo-orosomucoid in plasma}

Each blood sample was transferred to a microfuge tube, and plasma was separated by centrifugation. All specimens were assayed in duplicates. Total radioactivity was determined in a Kontron liquid scintillation counter (Betamatic Intertechnique, Trappes, France) using $30 \mu \mathrm{l}$ of plasma and $10 \mathrm{ml}$ of Dynagel (Comptoir Lyonnais de Verreries, Interbio, Lyon, France) as the scintillant. Deproteinization was carried out with $40 \mu \mathrm{l}$ of $10 \%(\mathrm{w} / \mathrm{v})$ phosphotungstic acid in $2 \mathrm{~N} \mathrm{HCl}$ and
$40 \mu \mathrm{l}$ of plasma. After $30 \mathrm{~min}$ at room temperature, the mixtures were centrifuged. Non-protein radioactivity was counted in $40 \mu \mathrm{l}$ of the supernatant fluid. Protein-bound radioactivity was calculated from the difference between total and non-protein radioactivity.

\section{Statistical analysis}

Results from $n$ experiments were expressed as mean \pm standard error (mean $\pm S E M$ ). Student's t-test for unpaired samples was used for analysis, with a level of significance at $p<0.05$.

A visual inspection of the labelled plasma concentration versus time in linear and semi-logarithmic scales shows a profile typical for a Michaelis-Menten elimination kinetic. This is the reason why the disappearance kinetics of ${ }^{3} \mathrm{H}$ ASOR were fitted to the model:

$\frac{\mathrm{dy}}{\mathrm{dt}}=\frac{V m \hat{y}}{\mathrm{~K}_{\mathrm{M}}+\hat{\mathrm{y}}}$

where $V m$ is the maximum elimination rate and $K_{M}$ is the concentration of ${ }^{3} \mathrm{H}$ ASOR corresponding to an elimination rate equal to half to $\mathrm{Vm}$. The dispersion error on the measured concentrations was not fully known, so we decided to estimate the $\mathrm{Vm}$ and $\mathrm{K}_{\mathrm{M}}$, minimizing the $\log$ likelihood function:

$\mathrm{L}=\mathrm{Z} \frac{(\mathrm{yi}-\hat{\mathrm{y} i})^{2}}{\mathrm{Vi}^{2}}+\lg \mathrm{Vi}$

where $\mathrm{Vi}$ is the error variance of the $\mathrm{i}$-th observation yi.

Note that usually weighted least squares are appropriately used when it is assumed that the error variance is known up to a proportional factor.

In our case the error variance is not known, so according to Skeiner [10] the following variance model was assumed.

$\mathrm{Vi}=a \hat{y}^{\mathrm{b}}$

where $a$ and $b$ are variance model parameters. These parameters as well as Vm and $\mathrm{K}_{\mathrm{M}}$ were estimated using the PHARM program [11].

\section{Results}

\section{Evaluation of the orosomucoid level and the percentage of its desialylation in normal and diabetic rat sera}

The orosomucoid content of normal rat sera was $152 \pm$ $23 \mathrm{mg} / 1(n=8)$ and $154 \pm 24 \mathrm{mg} / 1(n=8)$, by EID and RID respectively, whereas in diabetic rats the serum orosomucoid content was $379 \pm 129 \mathrm{mg} / 1(n=7)$ by both methods. Compared to normal rats the orosomucoid level was significantly higher $(p<0.001)$ in diabetic rats. In contrast, the percentage of underevaluation by EID relative to RID indicating the degree of desialylation of orosomucoid was found to be within the normal range in both normal and diabetic rats. No accumulation of partially desialylated orosomucoid occured in diabetic rat serum.

\section{Relationship between dose and removal of ${ }^{3} \mathrm{H}$ asialo-orosomucoid in control and diabetic rats}

In the first set of experiments, increasing quantities of ${ }^{3} \mathrm{H}$ ASOR were injected to find the dose at which the liver could no longer eliminate the protein in a matter of 


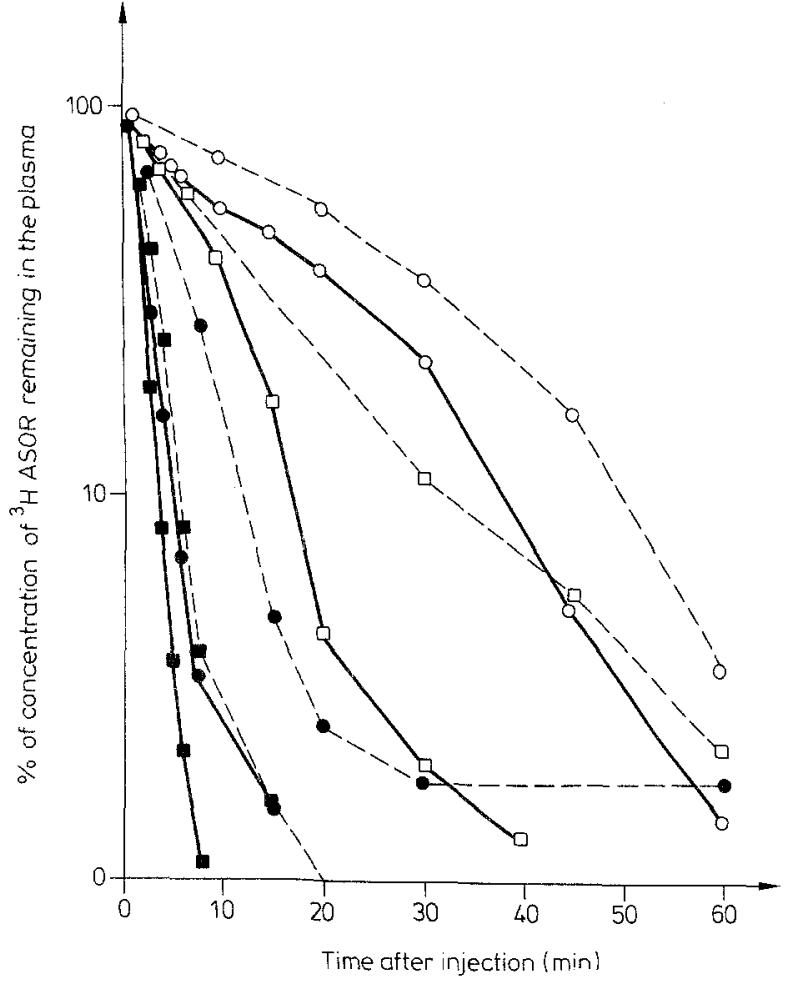

Fig. 1. Protein-bound radioactivity in the plasma of control rats (-) and diabetic rats (- - - ) which received different quantities of ${ }^{3} \mathrm{H}$ asialo-orosomucoid (ASOR). The doses, expressed per $100 \mathrm{~g}$ body wt. were: $75 \mu \mathrm{g}(\mathbf{\square}), 100 \mu \mathrm{g}(\bigcirc), 400 \mu \mathrm{g}(\square)$ and $1000 \mu \mathrm{g}(\mathrm{O})$

minutes. The behaviour of ${ }^{3} \mathrm{H}$ ASOR in plasma is illustrated with some representative curves of the proteinbound radioactivity as a function of the dose (Fig.1). The $50 \%$ of ${ }^{3} \mathrm{H}$ ASOR remaining in blood was reached at later intervals as the dose of injected ${ }^{3} \mathrm{H}$ ASOR increased (e.g. with normal rats about $50 \%$ of injected cpm were present in blood at $2 \mathrm{~min}$ for $75 \mu \mathrm{g} / 100 \mathrm{~g}$, $2 \mathrm{~min} 30 \mathrm{~s}$ for $100 \mu \mathrm{g} / 100 \mathrm{~g}, 8 \mathrm{~min}$ for $400 \mu \mathrm{g} / 100 \mathrm{~g}$ and $15 \mathrm{~min}$ for $1000 \mu \mathrm{g} / 100 \mathrm{~g}$ after injection). The kinetics of plasma disappearance of ${ }^{3} \mathrm{H}$ ASOR were dose-dependent. By administrating $1000 \mu \mathrm{g}$ of ${ }^{3} \mathrm{H}$ ASOR $/ 100 \mathrm{~g}$ of body weight in a single dose, we could see that the liver of normal rats maintained maximal disappearance rates for at least $20 \mathrm{~min}$.

\section{Plasma disappearance of ${ }^{3} \mathrm{H}$ asialo-orosomucoid in the presence of native orosomucoid}

Unlabelled native (sialylated) orosomucoid $(1000 \mu \mathrm{g})$ was simultaneously injected with $100 \mu \mathrm{g}$ of ${ }^{3} \mathrm{HASOR}$ in normal and diabetic rats (data not shown). No decrease in the coefficient of extraction of the labelled asialoglycoprotein was observed in either group of rats. The lack of competition between ASOR and orosomucoid indicates that these glycoproteins were cleared by different processes in both normal [12] and diabetic rats.
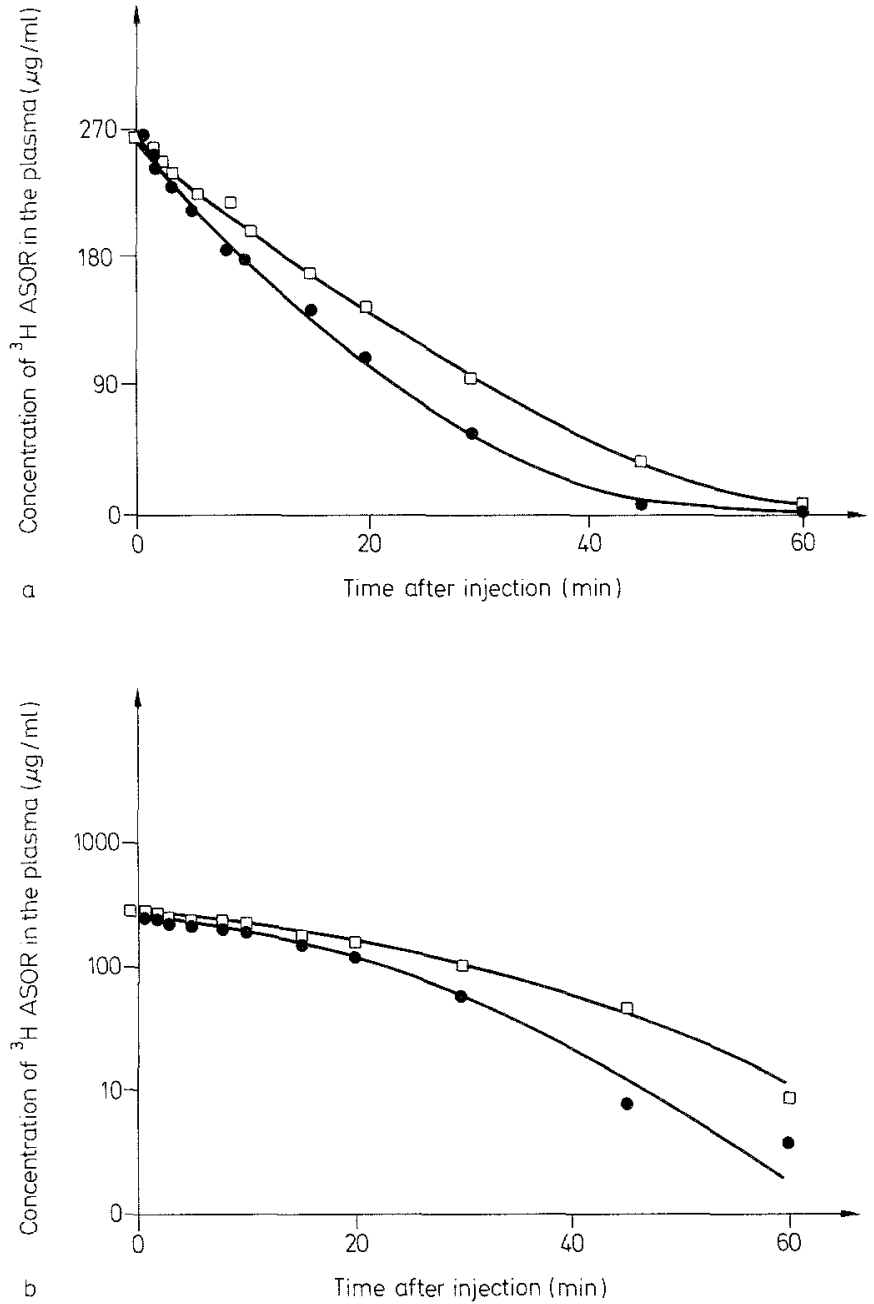

Fig. 2. Representative curves in linear (a) and logarithmic (b) scales of disappearance of the labelled protein from plasma of a control () and a diabetic rat ( $\square$ ). The dots are experimental dots and the lines are the result of the modeling according to the Michaelis-Menten equation

\section{Plasma disappearance of ${ }^{3} \mathrm{H}$ asialo-orosomucoid in control and streptozotocin-diabetic rats}

In this set of experiments a standard dose of $1000 \mu \mathrm{g}{ }^{3} \mathrm{H}$ ASOR per $100 \mathrm{~g}$ of body weight was administered to control $(n=7)$ and streptozotocin-treated rats $(n=6)$. The kinetic of disappearance was measured during $60 \mathrm{~min}$. In Figure 2, the curves are plotted in linear and semi-logarithmic scales. The dots are experimental dots and the lines are the results of the modeling according to the Michaelis-Menten equation.

The kinetic analysis provided the final parameter estimates Vmax and $K_{M}$ of ASOR removal from plasma in normal and diabetic rats (Table 1). ASOR was rapidly removed from bloodstream in normal rats, whereas in diabetic rats the asialoglycoprotein was cleared much more slowly. Mean values of $V \max =9.60 \pm 0.72 \mu \mathrm{g} /$ min per $100 \mathrm{~g}$ body wt. and $6.70 \pm 0.72 \mu \mathrm{g} / \mathrm{min}$ per $100 \mathrm{~g}$ body wt. were obtained for normal and streptozotocindiabetic rats respectively, and were statistically signifi- 
Table 1. Comparison of the maximal rates (Vmax) and the Michaelis constants $\left(\mathrm{K}_{M}\right)$ for the control and diabetic rats for our in vivo study and for our previous in vitro study $[1,12]$

\begin{tabular}{|c|c|c|c|c|}
\hline & \multicolumn{2}{|c|}{ In vivo studies } & \multicolumn{2}{|c|}{ In vitro studies } \\
\hline $\mathrm{K}_{\mathrm{M}}(\mathrm{nmol} / \mathrm{l})$ & $1.88 \pm 0.31$ & $1.44 \pm 0.31$ & $2.27 \pm 0.43$ & $2.32 \pm 0.53$ \\
\hline
\end{tabular}

${ }^{\text {a }} p<0.05$

cant at $p<0.05$. In contrast, the estimates of $\mathrm{K}_{\mathrm{M}}$, $1.88 \pm 0.31 \mathrm{nmol} / 1$ and $1.44 \pm 0.31 \mathrm{nmol} / 1$ for normal and diabetic rats respectively were not significantly different.

Phosphotungstic acid-nonprecipitable radioactivity was simultaneously evaluated and expressed as a percentage of the total radioactivity. Within the initial $30 \mathrm{~min}$, no significant protein-unbound radioactivity was detected in the plasma of both normal and diabetic rats. The percentage then increased and reached $50-60 \%$ at $60 \mathrm{~min}$ and remained constant in both groups of rats. This finding seems to indicate that, after the uptake of ASOR by tissues [1,12,13], the intracellular catabolism of ASOR and the subsequent elimination of radiolabelled metabolites were not apparently altered in diabetic rats [4].

\section{Discussion}

The present study provides in vivo estimates of the kinetic parameters of ASOR removal from plasma of diabetic rats. The effects of insulin treatment were not studied here. In fact, we have previously shown that insulin therapy of streptozotocin-diabetic rats restored the ability of isolated hepatocytes to bind and take up ${ }^{3} \mathrm{H}$ ASOR, and that the withdrawal of insulin led again to a decreased binding and uptake of ${ }^{3} \mathrm{H}$ ASOR [3].

Several aspects of these in vivo studies are in agreement with our in vitro studies [3]. First, the maximal rate of removal of ASOR $(\operatorname{Vmax}=6.70 \mu \mathrm{g} / \mathrm{min}$ per $100 \mathrm{~g}$ of body wt.) from plasma of diabetic rats was significantly lower than that of normal rats $(\operatorname{Vmax}=9.60 \mu \mathrm{g} / \mathrm{min}$ per $100 \mathrm{~g}$ of body wt.). Second, no modification of Michaelis constant was noted in diabetic rats. These data could be explained either by the presence of desialylated orosomucoid in the plasma, which competes with ${ }^{3} \mathrm{H}$ ASOR, or by a decreased blood flow or by a decreased uptake of ASOR by some tissues, mainly the liver.

The first hypothesis is ruled out since, despite an increased amount of plasma orosomucoid which was previously described $[5,6]$, no asialo-orosomucoid was detected. The second explanation is not retained, with a decreased blood flow never being described in diabetic rats. The third suggestion is the most relevant, taking into account our previous data showing a decreased num- ber of asialoglycoprotein receptors with diabetic rat hepatocytes. Since the major site of catabolism of injected asialoglycoproteins is the liver with the kidney and the gut participating to a much lower extent $[12,13$, 14], it appears that the disappearance of ASOR from plasma approximately represents the capacity of liver to bind and internalize asialoglycoproteins.

In order to compare adequately the maximal rate of removal of ${ }^{3} \mathrm{H}$ ASOR from plasma to the maximal rate of endocytosis of ${ }^{3} \mathrm{H}$ ASOR by hepatocytes, the last parameter was expressed as $100 \mathrm{~g}$ of body weight. Assuming a rat liver is $1.6 \times 10^{8}$ hepatocytes $/ g$ and a standard weight for a liver of $250 \mathrm{~g}$ rats is $7 \mathrm{~g}$, the maximal rates of endocytosis of ${ }^{3} \mathrm{H}$ ASOR become $0.80 \pm 0.09$ and $0.32 \pm 0.03 \mu \mathrm{g} / \mathrm{min}$ per $100 \mathrm{~g}$ of body weight in normal and diabetic rats respectively, which is ten- to twentyfold the maximal rate of removal of ${ }^{3} \mathrm{H}$ ASOR from plasma. This discrepancy between in vitro and in vivo studies was first described by Pardridge et al. [17], who suggested that, during the isolation procedure of hepatocytes, hepatic asialoglycoprotein receptors can undergo internalization.

In diabetic rats, the decreased rate of hepatic clearance of ${ }^{3} \mathrm{H}$ ASOR is not due to a reduced affinity of ASOR for its receptor but is rather related to a decreased number of functional receptors. Since the presence of sialic acid residues at the ultimate position of the receptor is needed to bind the galactose-terminated glycoproteins, an alteration of the carbohydrate moiety of membrane glycoprotein which occurs in experimental diabetes $[18,19,20]$ could be evoked. We previously demonstrated that the impairment of the uptake of ASOR was not related to a decreased membrane sialic acid content [20]. On the other hand, the variations in the number of asialoglycoprotein receptors could be related to the regulatory mechanism of insulin on protein synthesis [21] and/or breakdown [22, 23]. Diabetes mellitus leads to a decreased rate of synthesis of extra and intrahepatic proteins as well as to an increased rate of protein catabolism.

The alterations in the number of asialoglycoprotein receptors we observed with the in vitro model are markedly confirmed by the present in vivo experiments.

Acknowledgments. We wish to thank Dr. Wickerhauser (American Red Cross, NIH, Bethesda, MD, USA) for his generous gift of human 
orosomucoid, and Professor D. Durand for his training in the procedure of catheterization. This work was supported by a grant from the Centre National de la Recherche Scientifique UA 040622.

\section{References}

1. Ashwell G, Morell AG (1974) The role of surface carbohydrates in the hepatic recognition and transport of circulating glycoproteins. Adv Enzymol 41: 99-128

2. Schwartz AL (1985) The hepatic asialoglycoprotein receptor. CRC Crit Rev Biochem 16: 207-233

3. Dodeur M, Durand D, Dumont J, Durand G, Féger J, Agneray J (1982) Effects of streptozotocin-induced diabetes mellitus on the binding and uptake of asialo-orosomucoid by isolated hepatocytes from rats. Eur J Biochem 123: 383-387

4. Dodeur M, Coumoul S, Durand D, Durand G, Féger J, Agneray J (1983) Diabetes induced variation in hepatic binding protein. Biochem Biophys Res Comm 115: 82-86

5. Zeitlin PL, Hubbard AL (1982) Cell surface distribution and intracellular fate of asialoglycoproteins: a morphological and biochemical study of isolated rat hepatocytes and mono-layer cultures. J Cell Biol 92: 634-647

6. Mancini G, Carbonara AO, Heremans JF (1965) Immunochemical quantitation of antigens by single radial immunodiffusion. Immunochemistry 2: 235-254

7. Laurell CB (1966) Quantitative estimation of proteins by electrophoresis in agarose gel containing antibodies. Anal Biochem 15: 45-52

8. Biou D, Monnet D, Millet F, Féger J, Durand G (1984) An immunochemical procedure to evaluate the degree of desialylation of alpha ${ }_{1}$ glycoprotein in rat serum. J Immunol Methods 74: 267-271

9. Wilder RL, Yven CC, Subbarao B, Woods VL, Alexander CB, Mage RG (1979) Tritium radio-labelling of protein A and antibody to high specific activity: application to cell surface antigen radioimmunoassays. J Immunol Methods 28: 255-263

10. Skeiner LB, (1981) ELSFIT Users Manual. Division of Clinical Pharmacology, University of California, San Francisco

11. Gomeni R (1984) PHARM, an interactive graphic program for individual and population pharmacokinetic parameter estimation. Comput Biol Med 14: 25-34

12. Clarenburg R (1983) Asialoglycoprotein receptor is univolved in clearing intact glycoproteins from rat blood. Am J Physiol 244: G247-G253
13. Regoeczi E, Debanne MT, Hatton MWC, Koj A (1978) Elimination of asialofetuin and asialo-orosomucoid by the intact rat. Quantitative aspects of the hepatic clearance mechanism. Biochim Biophys Acta 541: 372-384

14. Dodeur M, Coumoul S, Scarmato P, Durand G, Féger J, Agneray $\mathrm{J}$ (1984) Asialo-orosomucoid degradation by normal and diabetic rat hepatocytes. Eur J Biochem 140: 577-581

15. Jonsson A, Wales JK (1976) Blood glycoprotein levels in diabetes mellitus. Diabetologia 12: 245-250

16. Guzdek A (1979) The influence of experimental diabetes on the serum and urinary glycopeptide compounds in rats. Endocrinology $74: 316-322$

17. Pardridge WM, Van Herle AJ, Naruse RT, Fierer G, Costin A (1981) In vivo quantification of receptor-mediated uptake of asialoglycoproteins by rat liver. J Biol Chem 258: 990-994

18. Chandramouli V, Williams S, Marshall JS, Carter JR (1977) Cell surface changes in diabetic rats. Studies of lectin binding to liver cell plasma membranes. Biochim Biophys Acta 465: 19-33

19. Nassar K, Cheng S, Levy D (1981) The effect of diabetes on hepatocyte plasma membrane fluidity and Concanavalin A-induced agglutination. Exp Cell Res 132: 99-104

20. Durand G, Dumont JP, Appel M, Durand D, Davy J, Féger J, Agneray J (1980) Effect of streptozotocin diabetes on sialic acid and glycoprotein binding of isolated hepatocytes. Horm Metab Res 12: $247-251$

21. Jefferson LS (1980) Role of insulin in the regulation of protein synthesis. Diabetes 29: 487-496

22. Draznin B, Trowbridge M (1982) Inhibition of intracellular proteolysis by insulin in isolated rat hepatocytes. Possible role of internalized hormone. J Biol Chem 257: 11988-11993

23. Hutson NJ, Lloyd CE, Mortimore GE (1982) Degradation of intra and extrahepatic protein by livers of normal and diabetic mice: differential responses to starvation. Proc Natl Acad Sci USA 79: $1737-1741$

Received: 15 October 1985

and in revised form: 22 April 1986

Professor G. Durand

UER des Sciences Pharmaceutiques

Laboratoire de Biochimie

5 rue J.B. Clément

92296 Châtenay-Malabry Cédex

France 